\title{
Role of Social Interaction in the Barriers Facing First-year International Students in the United States
}

\section{Mr. Johnny Crayd Woods Jr., Virginia Polytechnic Institute and State University}

Johnny C. Woods, Jr. is a Higher Education Ph.D. Student and a Graduate Research Assistant in the Department of Engineering Education at Virginia Tech, Blacksburg, Virginia. His research interests are STEM Education; Migration and Immigration issues in education; and Quality Assurance.

\section{Dr. Homero Murzi, Virginia Polytechnic Institute and State University}

Homero Murzi is an Assistant Professor in the Department of Engineering Education at Virginia Tech. He holds degrees in Industrial Engineering (BS, MS), Master of Business Administration (MBA) and in Engineering Education $(\mathrm{PhD})$. Homero has 15 years of international experience working in industry and academia. His research focuses on contemporary and inclusive pedagogical practices, industry-driven competency development in engineering, and understanding the barriers that Latinx and Native Americans have in engineering. Homero has been recognized as a Diggs scholar, a Graduate Academy for Teaching Excellence fellow, a Diversity scholar, a Fulbright scholar and was inducted in the Bouchet Honor Society.

\section{Ms. Maia Greene-Havas, Virginia Polytechnic Institute and State University}

Maia Greene-Havas is an Academic and Career Advisor in the Engineering Education department at Virginia Tech. She earned her Bachelor of Arts in Psychology from The Ohio State University. She earned her Masters plus thirty in School Psychology at Towson University. She worked as a school psychologist in the metro Washington D.C. area for five years and now serves as an Academic and Career Advisor in the College of Engineering at Virginia Tech.

\section{Mr. Abram Diaz-Strandberg, Virginia Tech Department of Engineering Education}

Abram is a Ph.D. student in the Virginia Tech department of engineering education. He holds a degree in mechanical engineering (B.S.) from The New Mexico Institute of Mining and Technology. His research interests include inclusive and creative pedagogies, teaching and learning for mastery, and transfer students, all with a focus around community college environments.

\section{Sophia Vicente, Virginia Polytechnic Institute and State University}

Sophia is a first-year Ph.D. student in Engineering Education at Virginia Tech. She is a member of the ECLIPS lab and an instructor for the Center for the Enhancement of Engineering Diversity. She holds a Bachelor of Science in Industrial Engineering from the Pennsylvania State University. 


\title{
Role of Social Interaction in the Barriers Facing First-Year International Students in the United States
}

\begin{abstract}
The United States (U.S.) is the top host nation for international students; however, the threshold of international students' mobility to the U.S. is currently on the decline. Research demonstrates that international students, mainly first-year students, encounter several barriers in adapting to the new academic environment in host nations. Social interaction is a critical means through which international students can easily adapt. Therefore, in this qualitative study, we explore how international students perceive their social interaction and the barriers they face in their first year of study in the U.S. We framed the study using the lens of Vygotsky's sociocultural theoretical framework and applied the case study approach. We conducted semi-structured interviews with 10 international students from the general engineering department in a single university in the South of the U.S. Our results account for the patterns that emerged from the data including socio-cultural adaptability, making friends, working in teams, and orientation structuration.
\end{abstract}

Keywords: International Students, First-Year, Social Interaction, Sociocultural Theory

\section{Introduction}

Academic migration is on the rise and involves students migrating to foreign countries in search of education. According to Contreras-Aquirre and Gonzalez [1], students are becoming more willing to move, travel, and pursue a degree in a foreign country. The Institute for International Education [2] infographics portray that the United States (U.S.), Canada, United Kingdom, China, Australia, France, Germany, Mexico, Netherlands, Spain, Russia, Finland, India, Japan, Sweden, and New Zealand are the main host nations for international students. Of these nations, the U.S. has experienced a decline in the number of international students, yet it remains by far the top host nation. The international student population plays an important role in the U.S. because of the unique assets they bring into the classrooms by providing a variety of insights based on their earlier academic and life experiences in their home countries [1], [3], [4]. Additionally, international students are major contributors to the U.S. economy. According to NAFSA Economy Tool [5], international students contributed \$39 billion to the U.S. economy in 2017 and helped the U.S. lead in technology and innovation.

As evident in the literature, the U.S. is a country that hosts and benefits a lot of international students. Several studies have been done on this population [1], [3], [4], [5], [7]. However, providing educational services to foreigners imposes new requirements on institutions to support international students in their educational and professional adaptation [6]. As international students studying within a different context, there are several barriers that institutions need to consider that are specific for this population of students, including fostering engagement in a new social and academic environment [4]. Furthermore, as previously mentioned, the U.S. has experienced a decline in the global share of international students from $28 \%$ in 2001 to $24 \%$ in 2017 [2]. This decline portrays the lack of growth in the percentage share of international 
students for the U.S., and has been attributed to a number of factors including the political environment in the U.S. and strong competition from other host countries [7]. Hence, in order to maintain leadership as the most desired location for international students, U.S. institutions need to deeply understand the challenges that may be impacting international students and how to better support them. The overarching goal is to advocate for a more positive experience for current international students in order to increase attraction to higher education institutions in the U.S. and to increase the quality of their experience. It is from this backdrop that this study was conducted.

The purpose of this study was to understand how international students perceive the barriers they face in their first year of study in the U.S. More specifically, this research sought to answer the research question: What are the perceptions of first-year international students regarding their social interaction and the barriers that they face in the U.S.? To answer the research question, we took a qualitative approach. A case study was used and data were collected through semistructured interviews with first-year international students at a major research university. The research is framed using the lens of Vygotsky's [8] sociocultural theoretical framework.

\section{Literature Review}

International students add value to campuses in terms of academic, cultural, and social dimensions; thus, the significance of embracing this student population [9]. According to the authors, the U.S. has experienced an increase in the international student population which requires new considerations to meet their educational needs. However, according to Zong and Batalova [7], the U.S. experienced a four percent decline in 2017 while the worldwide international student population doubled. As the U.S. percentage share of international students declines, other host nations experience rising numbers in their threshold of international students [2]. Considering the contributions of international students to the U.S, the declining trend is a missed opportunity, as it impacts the U.S. in a number of ways (i.e. economy, educational culture, technological innovation).

International students become exposed to potential difficulties while studying abroad in a different cultural, social, and linguistic environment [10]. Biserova and Shagivaleeva [6] explain that student adaptation is one of the most critical components of educational inclusion, and should be given consideration when dealing with international students. Akanwa [11] described the challenges face by international students in western developed countries as "differences in culture, language barriers, adjustment problems, medical concerns, pedagogical challenges, housing issues, lack of support services, and financial difficulty" (p. 271). In addition to these, Sovic [10] also suggested that academic shock, which focuses on how well students transition to a different academic environment (i.e. teaching and learning, and interaction with peers), is another important challenge face by international students. International students find initiating interaction with their peers challenging and this is especially prevalent when there is a lack of common cultural knowledge or experience [12]. Language has also been found to bar international students from successfully interacting with their peers from host nations even beyond the first-year [13].

Bierwiaczonek and Waldzus [14] indicated that awareness of the challenges facing international 
students is critical to enable educators at higher education institutions to determine measures that help students overcome challenges and improve standards for successful engagement into educational and professional activities. Similarly, Freeman and Li [15] found that first-year international students" "transition was hindered due to insufficient opportunities for meaningful classroom interactions and lack of academic instruction and feedback" (p. 19); and suggested that educators should consider inclusive pedagogies that accommodate the needs of students from diverse backgrounds. Additionally, several factors such as rising cost of higher education in the U.S., immigration rigidity with visas, unwelcoming policies, and political climate for immigrants and international students need to be added to the equation that contributes to the major challenges that international students face [7]. On the other hand, "the need for international students to take advantage of all the opportunities provided by their host institutions in order to improve themselves academically, socially, and otherwise" is emphasized by Akanwa ([11], (p. 282). While the U.S. still remains the top host nation for international students with about 1.1 million of the global 4.6 million in 2017 [2], it is experiencing the slowest pace in the threshold of international students' mobility since the 2009-2010 academic year [7], [9].

\section{Theoretical Framework}

This study is grounded in Vygotsky's sociocultural theory [8]. Vygotsky's sociocultural theory is relevant to help us answer our research question because it espouses that: social interaction (with consideration to the role of social factors such as interaction with peers, language, and culture) is fundamental in the development of cognition [8]. We considered this theory relevant to our research because of the focus of this study on understanding the barriers of first-year international students who are transitioning to a new environment for academic reasons, where their social interaction may involve dealing with a new culture, a different language, and people that are different from them.

The major themes of Vygotsky's theoretical framework are centered on the idea that learning occurs through social interaction within the society and culture, and the Zone of Proximal Development (ZPD) impacts the potential for cognitive development. The theory suggests that learning occurs at two levels; 1) interaction with others helps to structure individual cognition and development, and 2) the ZPD process which represents the need for guidance from external sources (i.e. teacher or more experienced peer) to help a cognitively prepared individual to fully develop.

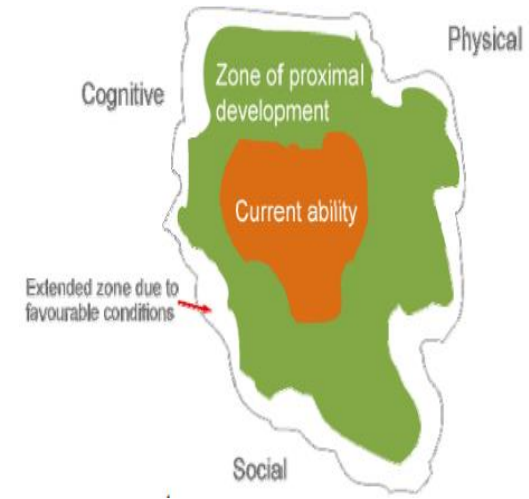

Figure 1. Vygotsky's Zone of Proximal Development [8]. 
According to Polly, Allman, Casto, and Norwood [16], the social-cultural theory provides three main interrelated but non-hierarchical themes including human development and learning originate in social, historical, and cultural interactions; use of psychological tools, particularly language, mediate development of higher mental functions; and learning occurs within the Zone of Proximal Development. Vygotsky's sociocultural theory accounts for the distance between learners' independent problem-solving abilities and when they are engaged with peers or under the guidance of an adult [17]. This theoretical assertion is important for this study due to its focus on the role that social interaction plays in the experience of international students.

The sociocultural setting along with an individual's ability to meaningfully engage in activities within that setting depicts development and learning [8]. Extensive research has also been done on Vygotsky's sociocultural theory, expanding on its significance to learning and development. Obina [14] emphasized that social-cultural theory provides insight into how cultural beliefs and attitudes can improve instruction and learning, stressing that learning and development occur when the opportunity exists for one to socially interact with members of their culture. According to McLeod [17], individual development (human intelligence) is made up of the society and culture in which they live, with the community being an essential component towards makingmeaning. Therefore, using Vygotsky's sociocultural theoretical framework contributes largely to exploring the role of social interaction in the barriers that first-year international students face when interacting and trying to gain education in a new and different environment.

\section{Methods}

To answer the research question, a qualitative research approach was adopted for the study, grounded in the case study methodological framework. The case study approach was used to explore the role of social interaction in the barriers facing first-year international students in the U.S. Case study research is based on the examination of a phenomenon by using data directly from the participants that experience it [18], based on the examination of the context and complexity of the real-world setting of the phenomenon in order to have an integral understanding of it [18], [19]. Hence, case study was used due to its specificity to context and given its usefulness to better understand and explain the experiences of specific cases or groups such as first-year international students in the U.S. Hence, the unit of analysis for the study are 10 first-year international students (participants) from a single university in Southern U.S.

Participants' details by gender and country of origin are provided in Table 1. Participants were first-year engineering students enrolled in a general engineering program and were recruited via email, following Institutional Review Board (IRB) approval. Each participant was given a \$15 (USD) gift card after the interview. Interviews were audio-recorded, transcribed verbatim, and all data collected were kept confidential and used for research purposes only. 
Table 1. Participants' Details by Country of Origin and Gender

\begin{tabular}{|l|l|l|l|}
\hline $\begin{array}{l}\text { Country (ies) of } \\
\text { Origin }\end{array}$ & Male & Female & $\begin{array}{l}\text { No. of } \\
\text { Participants }\end{array}$ \\
\hline China & 3 & 0 & 3 \\
\hline India & 1 & 1 & 2 \\
\hline Brazil & 1 & 0 & 1 \\
\hline Vietnam & 1 & 0 & 1 \\
\hline Argentina/Chile & 1 & 0 & 1 \\
\hline Kazakhstan & 0 & 1 & 1 \\
\hline India/Saudi Arabia & 1 & 0 & 1 \\
\hline
\end{tabular}

We recognize the low frequency of female participants in our study. However, the proportion of female participants in the study is reflective of the overall proportion of female students (21\%) in the college of engineering where the study was undertaken. Moreover, we were focused on prioritizing a broad representation of countries in the selection of participants.

\section{Data Collection}

Data were collected using an interview protocol after it was piloted and approved by the IRB. The interview protocol was developed using Vygotsky [8] sociocultural theoretical framework as a reference and enabled us to conduct semi-structured interviews with 10 first-year international students during the first semester (Fall) of the academic year 2018-2019. The semi-structured interviews asked specific questions guided by prompts upon which the richness of the interview was heavily dependent [20]. The interview protocol focused on the experiences of first-year international students in terms of their interaction with peers and the larger university community as well as the barriers that they encountered in adapting to their new educational environment. Specifically, prompts centered on eliciting concrete descriptions of students' experiences with classes, developing friendships, adapting to the new socio-academic culture, and the orientation process. The interviews lasted approximately 45 minutes and were conducted after students signed a consent form, in a venue of mutual agreement.

\section{Data Analysis}

Data were analyzed using the Dedoose qualitative data analysis software for the application of the thematic analysis method. This allowed us to gather major patterns that emerged from the data and classified them into themes based on meaning. Robson and McCartan [21] described the analysis as the act of giving meaning to data which involves a process of coding; deriving and developing concepts from data. Specifically, coding was conducted by three researchers individually. To ensure the reliability of the coding process, the three researchers conducted a second round of coding, reviewing initial codes for a deeper analysis of the data and to assign meaning to codes based on themes. This strategy was employed based on Robson and McCartan [21] analytical tool of questioning the data which enabled us to probe the data and develop provisional answers from the data. Codes that expressed related meanings were then grouped into categories and a codebook with assigned meaning for each coding category was developed. 
Table 2. presents the codebook along with the description for each code and a sample excerpt from our study.

Table 2: Coding categories, description of categories, and sample excerpts from students

\begin{tabular}{|l|l|l|}
\hline Code & Description & Sample Excerpt \\
\hline $\begin{array}{l}\text { Socio-cultural } \\
\text { Adaptability }\end{array}$ & $\begin{array}{l}\text { Experiences in assimilating to the new } \\
\text { environment; interaction with the } \\
\text { people and other cultural facets such } \\
\text { as language. }\end{array}$ & $\begin{array}{l}\text { "There are some different culture } \\
\text { stuffs, so, and my English is not very } \\
\text { well, so I can't, cannot write, I mean, } \\
\text { just communicate, just um, have a } \\
\text { little bit problem." }\end{array}$ \\
\hline $\begin{array}{l}\text { Making } \\
\text { Friends }\end{array}$ & $\begin{array}{l}\text { Experiences of interactions and } \\
\text { relationships with U.S students. } \\
\text { Teams }\end{array}$ & $\begin{array}{l}\text { "In engineering especially, it is so } \\
\text { hard to get close with people because } \\
\text { you start talking to them and the } \\
\text { subject just does not get any deeper." }\end{array}$ \\
\hline $\begin{array}{l}\text { Orientation } \\
\text { Structuration }\end{array}$ & $\begin{array}{l}\text { Pellaborating with U.S. peers in group } \\
\text { projects. } \\
\text { structure/organization of orientation. }\end{array}$ & $\begin{array}{l}\text { "I was in high school we write our } \\
\text { paper by our own, and when I go here } \\
\text { we write it together. And that time, I } \\
\text { just a little bit nervous about that. }\end{array}$ \\
\hline & $\begin{array}{l}\text { "It's all international students there } \\
\text { and then Americans because we don't } \\
\text { get the chance to ... We get the } \\
\text { chance but it's different because we } \\
\text { already met friends. So we're going } \\
\text { to be with them." }\end{array}$ \\
\hline
\end{tabular}

The codebook (Table 2) presents the operationalized definition of codes and gives a broader view of the role of social interaction among first-year international students' experiences and perceptions of the challenges they face studying in the U.S.

\section{Research Quality}

A set of procedures account for measures we applied to mitigate our limitations so as to ensure the quality of the research. Three researchers analyzed the data individually and created several themes from the data. To ensure inter-coder reliability, we compared initial individual codes; in instances when codes did not match, researchers discussed the codes until an agreement was reached. The themes were then compared and analyzed to establish a final set of themes agreed by the larger team of researchers as well as the codebook presented in Table 2. As such, codes and themes were decided by the entire research team. The credibility of the findings was determined to be aided by the immediacy of the interview. Students were interviewed in the first weeks of their study at the university, allowing the interviews to capture their initial experiences promptly. The confirmability of the results was strengthened based on data analysis, deliberation, and agreement by the entire research team. 


\section{Results}

Our results account for how first-year international students perceive the role of social interaction in the barriers that they face while attending school in the US. Thus, we focus on the perception of relationships and interaction with others, including students and the larger university community. We present the results in four categories (socio-cultural adaptability, making friends, working in teams, and orientation structuration) based on the patterns that emerged from the data.

\section{$\underline{\text { Socio-cultural Adaptability }}$}

Socio-cultural adaptability reflects students' views of the challenges experienced in assimilating to the new environment. Most common themes emanating from students' expressions deal with perceptions of their interaction with people and other cultural facets such as language. As an example of perceptions of people, a student indicated: "As I told you, it's a lot harder to get close to Americans than it is to [country national], and I am used to [country national]. So, adapting to that was a little bumpy." Another student indicated that: "I think every international student has this nervousness of talking to a national, here, because we're not sure as to how we're going to be perceived."

In describing the issues related to cultural challenges in their interactions, one student mentioned: "Maybe just getting to know new people and a new language. Away from home. Separated from my parents, because I came here by my own ... Away from my friends and everything. Just like breaking the ice I would say." Another student indicated that:

I will say personal space for me because even if we are neighbors, we sometimes go to the neighborhoods, just go straight to the people's houses to say hi. Or a stranger we just touch and go in front of them and stuff, but here if you want to be close to someone, you have to suddenly ask permission to be close to them, to touch their personal space. The personal space here really serious!

Adapting to a new environment can be challenging. First-year international students become exposed to a different culture other than their normal way of life while pursuing their academic activities in a different country.

\section{Making Friends}

Making friends describes how international students expressed their interactions and relationships with U.S. students. The data showed that first-year international students experience difficulties in making friends with domestic students. For example, a student said:

I don't know the relationship just doesn't develop. That's what I've noticed so far. Even if you go out with them, it still remains the same. It doesn't really bother me ... I'm a lot more focused on my goal than I am on making friends. 
Another example included a student who indicated: "It is much easier for us to get close to people. I can't really explain why, but it's just not possible to become as close friends with Americans as it is with [country national]. It's just an interesting aspect." Expanding further on relationships with friends from the U.S, another student mentioned: "I do have roommate. Actually, he is American. At first, he's not really close. He don't really open because he's previously have a bad roommate."

Data revealed that making friends with U.S students is important for first-year international students as a student indicated: "I guess getting like as many relationships, getting friends, or getting help with economics and everything, and having a good time, obviously. Like spending time with friends and everything, it's key to feel like home here."

\section{Working in Teams}

Working in teams describes the classroom interaction of the students' experiences to collaborate with their peers from the U.S. in group projects. Our data revealed that first-year international students found it difficult to work in teams due to communication challenges and based on the format of academic activities in the US. For example, a student indicated:

Communicating to American students, cause one to one or one to two people, like three people group, it is good for me, but if there is over five person, they are talking each other, and I have no idea what they are talking about. So, it's hard to join the group chat here.

Similarly, another student commented: "I don't feel included with a group, or I just feel the group project we did, my group didn't make me participate, or they let me down, or everything." In terms of differences in the academic format, a student said:

So, I'm not used to this much interaction because classes in [Country] are usually much more individual. Let's put it like that. It's a group of course but ... each one is focused on his or her own work. So that is a big difference.

\section{Orientation Structuration}

Orientation structuration deals with the challenges expressed by students regarding how the orientation is structured. The most prevalent issues expressed by students include the provision of a lot of information to students in a one-day session, inconvenient class schedules, and failure to promote in-depth interaction between U.S. students and international students. For example, one student indicated: "One thing I would say probably a lot of information in a short interval of time...To comprehend so many resources for this, we have this or for this we have that. That was a little difficult." Commenting on the inconvenience of class scheduling, another student mentioned:

I think it was really helpful. It was fun. Most of the people that I talk to right now, I met at orientation, so I guess that's a big factor. But one thing that I actually wanted to bring up is a lot of international students, we talked about this, because 
international orientation happens after the regular freshman orientation and the classes that we get to pick, a lot of the times, are already either filled or have different inconvenient timings. That's actually a point that we wanted to bring up with the university in general.

Our results also show that orientation facilitated bonding, mainly among international students as compared with bonding between international students and U.S. students. For example, a student said: "I made just little friends but I don't stick too much with them... We do the international orientation we come first and then them. So, the people we met first, normally is the ones that we gonna be friends with."

\section{Discussion/Conclusion}

Overall, the study contributes to the body of literature and provides an understanding of the social barriers faced by first-year international students in the U.S. Socio-cultural adaptability, making U.S. friends, working in teams, and orientation structure emerged as the most prevalent barriers. Regarding socio-cultural adaptability, students shared many aspects in which living within a new culture impacts their transition to university, such as navigating a new language and cultural differences such as personal space. These challenges can impact students both inside and outside the classroom. As Ferrer [22] indicated, the normal development of learners in a different culture or group pertaining to a different culture may not be an adequate norm. It is important that students find a quick way to adjust to new ways of life when studying in a foreign country, as this directly affects their academic achievement.

International students expressed their willingness to interact with domestic students but found it challenging to make those connections. Relationships with peers who understand the existing context is important to help international students understand the society. Knowledge is socially constructed based on interactions between the self and peers [23]. Thus, it provides a challenge to university professionals to create more opportunities to bring international and domestic students together early in their transition to university. This also calls universities to better prioritize inclusive practices in order for international and domestic students to more easily and quickly see the value that can result from their relationships with one another. It is also important for international students to build such awareness for themselves and seek to foster new relationships to fit within the society and culture [11]. Similarly, international students encounter barriers when asked to participate in course teamwork. Not only do language barriers and anxiety involving the use of a new language impact the communication between teammates, but not all international students also have prior experiences working with teams. This provides a challenge in that international students must quickly figure out how to maneuver this new way of learning in order to complete their assigned coursework. Instructors are therefore challenged with the task of providing enough structure to help international students figure out this new situation while also instilling lessons of working with others.

Considering that the overarching support networks that international students have are far away, orientation provides a fantastic opportunity for the development of new relationships that help build social support networks. Vygotsky's sociocultural theory speaks to the importance of such relationships. That being said, orientation also stands as a necessary opportunity to share the 
important information students must have to successfully embark upon their university experience. Given the feedback provided by students, it is in the best interest of university professionals to provide only critical information since the experience is already overwhelming.

First-year international students become more comfortable and therefore more academically successful through programs that help them to learn aspects of the new culture and language, foster friendship with their U.S. counterparts, navigate teamwork in the classroom, and provide meaningful orientation experiences. Study results lead to multiple implications for universities to consider when serving an international student population in order to address social barriers. Firstly, as they begin their transition to college it would be beneficial for programming to become available that would allow students to share and discuss their cultural observations and experiences. This would provide guidance to students as they process the culture in which they are newly entrenched and would offer support to students as their support systems shift. Secondly, hosting events that would encourage international and domestic students to interact would provide opportunities for not only the development of cross-cultural friendships but could also potentially lead to increased multi-cultural awareness. Thirdly, it is important for university professionals to receive a formal briefing on the intense transition period first-year international students experience in order to best support them, especially in the classroom. Finally, to get the most out of the available orientation period, universities are encouraged to carefully evaluate the information that is shared and should perhaps discover other means by which to share relevant and important information with international students following orientation. Host institutions are encouraged to help international students adapt to their surroundings by offering suitable institutional support programs that directly increase their emotional outcomes and school-life satisfaction [24]. 


\section{References}

[1] H. C. Contreras-Aguirre and E. Gonzalez Y Gonzalez, "Experiences of International Female Students in U.S. Graduate Programs," College Student Journal, vol. 51, no. 1, pp. 33-46, 2017.

[2] Institute for International Education, "Project Atlas: International student mobility," Institute for International Education (IIE). [Online]. Available: https://www.iie.org:443/en/Research-andInsights/Project-Atlas/Explore-Data/Infographics/Current-Infographics. [Accessed: 27-Jan-2020].

[3] Y. Kwon, "Factors affecting international students' transition to higher education institutions in the United States," College Student Journal, 01-Dec-2009. [Online]. Available: https://link.galegroup.com/apps/doc/A349308814/AONE?sid=lms. [Accessed: 27-Jan-2020].

[4] J. Wang, "A Study of Resiliency Characteristics in the Adjustment of International Graduate Students at American Universities," Journal of Studies in International Education, vol. 13, no. 1, pp. 22-45, Mar. 2009, doi: 10.1177/1028315307308139.

[5] "New NAFSA Data: International Students Contribute \$39 Billion to the U.S. Economy," NAFSA. [Online]. Available: https://www.nafsa.org/about/about-nafsa/new-nafsa-data-international-studentscontribute-39-billion-us-economy. [Accessed: 27-Jan-2020].

[6] G. K. Biserova and G. R. Shagivaleeva, "Socio-Psychological Adaptation of International Students to Learning and Professional Activities," Space and Culture, India, vol. 6, no. 5, pp. 99-114, Mar. 2019, doi: 10.20896/saci.v6i5.411.

[7] Jie Zong and Jeanne Batalova, "International Students in the United States," migrationpolicy.org, 08-May-2018. [Online]. Available: https://www.migrationpolicy.org/article/international-studentsunited-states. [Accessed: 27-Jan-2020].

[8] L. S. Vygotsky, Mind in Society: The Development of Higher Psychological Processes. Harvard University Press, 1980.

[9] H. Wu, E. Garza, and N. Guzman, "International Student's Challenge and Adjustment to College," Education Research International, 2015. [Online]. Available: https://www.hindawi.com/journals/edri/2015/202753/. [Accessed: 27-Jan-2020].

[10] S. Sovic, "Coping with stress: the perspective of international students," 19-May-2008. [Online]. Available: https://www.ingentaconnect.com/content/intellect/adche/2008/00000006/00000003/art00002. [Accessed: 27-Jan-2020].

[11] Akanwa, Emmanuel, "International students in western developed countries: History, challenges, and prospects.," Journal of International Students, vol. 5, no. 3, pp. 271-284., 2015.

[12] S. Arkoudis and C. Baik, "Crossing the interaction divide between international and domestic students in higher education," p. 17.

[13] Clare Wright and Alina Schartner, “'I can't ... I won't?' International students at the threshold of social interaction," Journal of Research in International Education, vol. 12, no. 2, pp. 113-128, 2013.

[14] K. Bierwiaczonek and S. Waldzus, "Socio-Cultural Factors as Antecedents of Cross-Cultural Adaptation in Expatriates, International Students, and Migrants: A Review," Journal of CrossCultural Psychology, vol. 47, no. 6, pp. 767-817, Jul. 2016, doi: 10.1177/0022022116644526.

[15] K. Freeman and Mingmin Li, "'We are a ghost in the class': First year International Students' Experiences in the Global Contact Zone,” Journal of International Students, vol. 9, no. 1, pp. 19-38, 2019.

[16] D. Polly, B. Allman, A. Casto, and J. Norwood, "Sociocultural Perspectives of Learning," in Foundations of Learning and Instructional Design Technology, 2017.

[17] Saul McLeod, "Vygotsky | Simply Psychology," Developmental Psychology, 2018. [Online]. Available: https://www.simplypsychology.org/vygotsky.html. [Accessed: 02-Feb-2020].

[18] J. M. Case and G. Light, "Emerging Research Methodologies in Engineering Education Research," Journal of Engineering Education, vol. 100, no. 1, pp. 186-210, 2011, doi: 10.1002/j.21689830.2011.tb00008.x. 
[19] R. K. Yin, Applications of Case Study Research. SAGE, 2011.

[20] C. Marshall and G. B. Rossman, Designing Qualitative Research. SAGE Publications, 2014.

[21] C. Robson and K. McCartan, Real world research. John Wiley \& Sons, 2016.

[22] J. P. • 2 Y. Ago, “The Sociocultural Theory of Lev Vygotsky," Steemit, 23-Jan-2018. [Online]. Available: https://steemit.com/psychology/@joseferrer/the-sociocultural-theory-of-lev-vygotsky. [Accessed: 27-Jan-2020].

[23] M. B. B. Magolda, "Evolution of a Constructivist Conceptualization of Epistemological Reflection," Educational Psychologist, vol. 39, no. 1, pp. 31-42, Mar. 2004, doi: 10.1207/s15326985ep3901_4.

[24] Yan, Z. and Sendall, P., "First year experience: How we can better assist first-year international students in higher education.," Journal of International Students, vol. 6, no. 1, pp. 35-51., 2016. 